\title{
Study on ventilation scheme and application during construction of high altitude gas tunnel
}

\author{
DONG Zhengbo ${ }^{1}$, CAI Shuang ${ }^{2}$, HU Juyi ${ }^{2}$, CHENG Liang ${ }^{2, *}$ \\ ${ }^{1}$ Qinghai Communications Construction Management Co, Ltd., Xining, Qinghai, 810003, China; \\ ${ }^{2}$ China Merchants Chongqing Communication Research \& Design Institute Co., Ltd., Chongqing 400067, China)
}

\begin{abstract}
It is the key and difficult point to ensure the safety of tunnel construction by ventilation in high gas tunnel construction in high altitude and cold area. Taking ning-chan high gas tunnel as the research object, the ventilation of the tunnel is calculated, the ventilation parameters are optimized, the ventilation equipment is selected according to the calculation results, the location of the ventilation equipment is optimized, and the reasonable construction ventilation scheme is determined. The results show that through the design of the above ventilation scheme and the control of the site, it can not only ensure the ventilation demand of the super long and high gas tunnel construction in the high cold and high altitude area, but also ensure the tunnel construction in winter, and effectively save the construction ventilation cost.
\end{abstract}

\section{Introduction}

During tunnel construction, it is often necessary to cross areas with complicated geological conditions. In the construction process of tunnels passing through coal measure strata, it is inevitable to encounter poisonous and harmful gases such as gas and hydrogen sulfide, which seriously affect the safety during tunnel construction ${ }^{[1-3]}$. Among them, high-gas tunnels and gas outburst tunnels bring great difficulties and potential safety hazards to tunnel construction, operation and disaster prevention. At present, construction of high-gas extra-long tunnels in cold and high-altitude areas is unprecedented in China, and there is no experience to follow, so it is necessary to study the safe construction technology of tunnels in depth ${ }^{[4-8]}$. In high-gas tunnels, there are not only high-concentration gas, but also highconcentration hydrogen sulfide, carbon monoxide and other toxic and harmful gases, so ventilation plays a crucial role. On the other hand, ventilation is also a challenge for high-gas long tunnels in high-latitude and cold areas ${ }^{[8-11]}$.

In this paper, Ningchan high-altitude high-gas tunnel is taken as the object of study. By analyzing the ventilation differences of high-altitude tunnels, the ventilation parameters of high-altitude tunnels during construction are calculated, the ventilation equipment is optimized, the reasonable construction ventilation scheme is determined, and engineering application is carried out for Ningchan Tunnel to verify the reliability of the ventilation scheme.

\section{Project overview}

Ningchan Tunnel is located between the Ningchan Pass and Ketu on the Xiaoshahe (Gansu-Qinghai border) Datong section of National Highway 569 MandelaDatong Highway. The left and right tunnels are $6024 \mathrm{~m}$ and $5943 \mathrm{~m}$ long respectively. The maximum sea level elevation of the tunnel site area is $4122 \mathrm{~m}$, and the lowest elevation is $3460 \mathrm{~m}$. It is a typical super-long highaltitude highway tunnel.

The surrounding rock at the entrance of Ningchan Tunnel is interbedded with strongly-moderately weathered carbonaceous shale (containing coal streak) and sandstone. The shale is of pelitic texture and thin stratified structure, while the sandstone is of mediumcoarse sand texture and medium thickness structure, partly intercalated with thin-bedded coal streaks. Affected by $\mathrm{F} 4$ fault, the joints and fissures in this section are extremely developed, the rock masses are broken and loose, and the stability of surrounding rocks is poor.

During the construction of advance geological drilling on ZK37+845 tunnel face in the left tunnel, a sudden gush of water vapor appeared when drilling holes $2 \mathrm{~m}$ away from the bottom plate at the left and right sides to $2.5 \mathrm{~m}$. The ejection distance from the left borehole was about $2.5 \mathrm{~m}$, and that of the right borehole was about $1 \mathrm{~m}$. The detection at the borehole gushing water vapor showed that the hydrogen sulfide concentration was as high as $100 \mathrm{PPm}$, and the gas concentration accounted for about $2.5 \%$. The tunnel was identified as a high-gas tunnel, which belongs to a high-risk tunnel. According to the data of geological exploration, there were $1400 \mathrm{~m}$ or

\footnotetext{
* Corresponding author: lightcheng@126.com
} 
even longer high gas sections in the follow-up left and right tunnels of Ningchan Tunnel.

\section{Ventilation parameter calculation and equipment selection}

\subsection{Calculation principle}

According to the Specifications for Design and Construction of Highway Tunnels with Gas ${ }^{[12]}$, the air volume required for construction ventilation in the highgas work area of highway tunnel is calculated separately according to the maximum headcount of simultaneous operations in the tunnel, the minimum allowable air velocity in the tunnel, the amount of blasting fume to be discharged for one-time blasting, the total power of internal combustion machinery and equipment and the gas emission rate. Take the maximum value as the required air volume, see Table 1 , and check the air velocity.

Table 1. Calculation Parameters of Ventilation in Tunnel Construction

\begin{tabular}{|c|c|c|c|}
\hline \multicolumn{2}{|c|}{ Item } & Unit & $\begin{array}{l}\text { Calculation } \\
\text { and control } \\
\text { parameters }\end{array}$ \\
\hline \multicolumn{2}{|c|}{$\begin{array}{c}\text { Minimum air velocity of tunnel } \\
\text { face }\end{array}$} & $\mathrm{m} / \mathrm{s}$ & 0.5 \\
\hline \multicolumn{2}{|c|}{ Tunnel face area } & $\mathrm{m}^{2}$ & 110 \\
\hline \multicolumn{2}{|c|}{$\begin{array}{l}\text { Required air volume per minute for } \\
\text { workers in the tunnel }\end{array}$} & $\begin{array}{c}\mathrm{m}^{3} / \mathrm{mi} \\
\mathrm{n}\end{array}$ & 4 \\
\hline \multicolumn{2}{|c|}{$\begin{array}{l}\text { Maximum gas emission rate of a } \\
\text { single tunnel }\end{array}$} & $\begin{array}{c}\mathrm{m}^{3} / \mathrm{mi} \\
\mathrm{n}\end{array}$ & 4.2 \\
\hline \multicolumn{2}{|c|}{$\begin{array}{l}\text { Allowable gas concentration at } \\
\text { working face }\end{array}$} & $\%$ & 0.5 \\
\hline \multicolumn{2}{|c|}{ Duct diameter } & $\mathrm{m}$ & 1.5 \\
\hline \multicolumn{2}{|c|}{$100 \mathrm{~m}$ air leakage rate of air duct } & $\%$ & 1 \\
\hline \multicolumn{2}{|c|}{$\begin{array}{l}\text { Harmful gases produced by } \\
\text { explosion }\end{array}$} & $\mathrm{m}^{3} / \mathrm{kg}$ & 80 \\
\hline \multicolumn{2}{|c|}{$\begin{array}{l}\text { Required air volume per } 1 \mathrm{~kW} \\
\text { internal combustion machinery }\end{array}$} & $\underset{\mathrm{n}}{\mathrm{m}^{3} / \mathrm{mi}}$ & 3 \\
\hline \multirow{4}{*}{$\begin{array}{l}\text { Construction } \\
\text { machinery and } \\
\text { equipment }\end{array}$} & Dump truck & $\mathrm{kw}$ & 202 \\
\hline & $\begin{array}{l}\text { Concrete } \\
\text { truck }\end{array}$ & kw & 202 \\
\hline & Excavator & $\mathrm{kw}$ & 100 \\
\hline & Loader & $\mathrm{kw}$ & 145 \\
\hline
\end{tabular}

\subsection{Calculation of required air volume}

1) Required air volume at minimum air velocity

Required air volume at minimum air velocity for step-by-step excavation of tunnel face:

$$
Q_{5 \mathrm{t}}=v \cdot A_{t}
$$

Where, $v$ is the minimum air velocity at the tunnel face, $\mathrm{m} / \mathrm{s} ; A_{t}$ is the excavation section of the tunnel upper bench, $\mathrm{m}^{2}$.

Required air volume at minimum air velocity on return air side:

$$
Q_{5 q}=v \cdot A_{q}
$$

Where, $v$ is the minimum air velocity of tunnel return air, $\mathrm{m} / \mathrm{s} ; A_{q}$ is the cross-sectional area of tunnel return air, $\mathrm{m}^{2}$.

2)Required air volume for diluting gas

$$
Q_{3}=Q_{C} \cdot K /\left(B_{g}-B_{g 0}\right)
$$

Where, $Q_{C}$ is the maximum gas emission rate of a single tunnel, $\mathrm{m}^{3} / \mathrm{min} ; K$ is the unbalance coefficient of gas emission, taking $2 ; B_{g}$ is the allowable gas concentration at the working face, $\% ; B_{g 0}$ is the gas concentration in the incoming air flow, $\%$.

3)Air volume required by workers in the tunnel

$$
Q_{1}=K \cdot M \cdot Q_{n}
$$

Where, $K$ is the air volume reserve factor, taking $1.2 ; \mathrm{M}$ is the number of people working simultaneously in the tunnel (taking 80); $Q_{n}$ is the amount of fresh air required per person per minute for the workers in the tunnel, taking $4 \mathrm{~m}^{3} / \mathrm{min}$.

4)Air volume required for blasting operation

$$
Q_{2}=\frac{2.25}{t} \sqrt[3]{\frac{G \cdot(A L)^{2} \cdot \psi \cdot b}{p^{2}}}
$$

Where, $\mathrm{p}$ is the duct air leakage coefficient, $p_{100}=1 \% ; L$ is the critical length, m; $L=12.5 \times \frac{G b K}{A P^{2}} ; \psi$ is the drenching coefficient, taking $0.8 ; \mathrm{b}$ is the amount of harmful gas generated when explosives explode, taking $80 \mathrm{~m}^{3} / \mathrm{kg}$; A is the crosssectional area of tunneling, $50 \mathrm{~m}^{2} ; \mathrm{G}$ is the quantity of explosives (kg) blasted simultaneously, where, $G=q \cdot v$; $\mathrm{q}$ is the amount of explosives consumed per cubic of rock blasted, taking $0.6 \mathrm{~kg} / \mathrm{m}^{3} ; v$ is the rock volume blasted, taking $75 \mathrm{~m}^{3} ; t$ is the ventilation time, taking $30 \mathrm{~min}$.

5)Air volume required for machinery

$$
Q_{4}=\sum_{1}^{n} q \times Q
$$

Where, $\mathrm{q}$ is the required air volume per $1 \mathrm{~kW}$ internal combustion machinery, taking $3 \mathrm{~m}^{3} / \mathrm{min} ; n$ is the number of internal combustion machinery, including 1 loader and 2 dump trucks; $Q$ is the power of a single internal combustion machinery, KW.

The ventilation speed in the tunnel should not be less than $0.5 \mathrm{~m} / \mathrm{s}$. The air volume required for construction ventilation in the gas work area should be calculated separately according to smoke from blasting, the maximum number of workers, the operation machinery, the minimum air velocity and the absolute gas emission rate, and the maximum value among them should be taken as the required air volume. According to calculation, the air volume required for gas tunnel construction under different working conditions is shown in Table 2. It can be seen from the table that the air volume required at the tunnel face is $1804 \mathrm{~m}^{3} / \mathrm{min}$ (calculated according to the total mechanical power in the tunnel). 
Table 2. Air Volume Required for Gas Tunnel Construction

\begin{tabular}{cc}
\hline Working condition & $\begin{array}{c}\text { Air volume } \\
\left(\mathrm{m}^{3} / \mathrm{min}\right)\end{array}$ \\
\hline $\begin{array}{c}\text { Maximum headcount of } \\
\text { simultaneous operations in the } \\
\text { tunnel }\end{array}$ & 240 \\
$\begin{array}{c}\text { Minimum allowable air velocity in } \\
\text { the tunnel }\end{array}$ & 1710 \\
$\begin{array}{c}\text { Amount of blasting fume to be } \\
\text { discharged for one-time blasting }\end{array}$ & 140.7 \\
$\begin{array}{c}\text { Total power of internal combustion } \\
\text { machinery and equipment } \\
\text { Absolute gas emission rate }\end{array}$ & 1804 \\
\hline
\end{tabular}

The tunnel is located in the plateau area, so low pressure, oxygen deficit and cold are the most important climatic characteristics. The rarefied air leads to the decrease of air pressure, which changes the properties of air accordingly [13]. With the increase of altitude, the atmospheric pressure decreases, the number of gas molecules per unit volume decreases, the air is thin, and the unit weight and density of the air decrease. There is the following relationship:

$$
\gamma_{Z}=\gamma_{0}\left(1-\frac{Z}{44300}\right)^{4.256}
$$

Where, $\gamma_{Z}$ is the air density at the altitude of $Z$, $\mathrm{kg} / \mathrm{m}^{3} ; \gamma_{0}$ is the air density at the altitude of $0 \mathrm{~m}$, taking $1.2 \mathrm{~kg} / \mathrm{m}^{3}$.

The altitude of the tunnel is $3501.51-3592.55 \mathrm{~m}$, with an average altitude of $3547.03 \mathrm{~m}$, so the air density at this altitude is $0.84 \mathrm{~kg} / \mathrm{m}^{3}$. Then, the density correction coefficient is: $\mathrm{k}=0.84 / 1.2=0.7$. Through altitude check, the actual air volume required in the tunnel is $1804 / 0.7=2577 \mathrm{~m}^{3} / \mathrm{min}$.

Air leakage coefficient: firstly, the ventilation from construction to shaft position is considered. Assuming that the maximum length of the air duct supplied by the fan to the tunnel face as $1300 \mathrm{~m}$, the air leakage coefficient is:

$$
P=1 /(1-\beta) L / 100=1.14
$$

Where, $\mathrm{L}$ is the air duct length, taking $1300 \mathrm{~m} ; \beta$ is the average air leakage rate of $100 \mathrm{~m}$, taking $1 \%$.

Air supply volume of fan:

$$
Q_{j}=P \times Q_{h}
$$

Where, $Q_{h}$ is the maximum value of each item in the calculation of air volume required for the working face, taking $2577 \mathrm{~m}^{3} / \mathrm{min}$.

At present, the air leakage coefficient for tunnel face air volume verification is:

$$
P=1 /(1-\beta) \cdot L / 100=1.07
$$

Where, $\mathrm{L}$ is the air duct length, taking $1300 \mathrm{~m} ; \beta$ is the average air leakage rate of $100 \mathrm{~m}$, taking $1 \%$.

Then the actual air volume at the tunnel face is:

$$
Q_{\text {Actual }}=60 \times V_{\text {Actual }} \times S
$$

Where, $V_{\text {Actual }}$ is the measured air velocity at the outlet of the air duct, taking $22 \mathrm{~m} / \mathrm{s}$; $\mathrm{S}$ is the crosssectional area of the air duct, taking $1.766 \mathrm{~m}^{2}$; it can be obtained through calculation that the actual air volume at the tunnel face is $2331.12 \mathrm{~m}^{3} / \mathrm{min}$, which shows that the current air supply volume can meet the actual demand.

\subsection{Air pressure calculation}

The fan is selected based on the total air pressure after considering ventilation resistance. The calculation process is as follows.

Total air pressure resistance of the tunnel:

$$
h_{\text {Total }}=h_{\text {Friction }}+h_{\text {total }}+h_{\text {total }}+h_{\text {Dynamic }}
$$

$$
\text { (1) Friction resistance: }
$$

$$
h=6.5 \alpha \frac{L Q^{2}}{d^{5}}
$$

Where, $\mathrm{Q}$ is the geometric average of fan suction air volume and outlet air volume of the air duct, $(49.8 \times 67.2)$ $1 / 2 \mathrm{~m}^{3} / \mathrm{s} ; \mathrm{d}$ is the duct diameter, and the main tunnel is provided with $1.5 \mathrm{~m}$ air duct; $\alpha$ is the friction coefficient of the duct, taking 0.0012 .

The diameter selected for the air duct is $1.5 \mathrm{~m}$, and $h_{\text {Friction total }}$ is calculated to be $4471 \mathrm{~Pa}$.

(2) Local resistance:

$$
h_{\text {local }}=\varepsilon \frac{v^{2}}{2} \gamma_{z}
$$

Where, $\varepsilon$ the local resistance coefficient after form change for a section, taking 1.64; $\gamma_{z}$ is the specific gravity of air, $0.84 \mathrm{~kg} / \mathrm{m}^{3}$; $\mathrm{v}$ is the average air velocity of the whole length of the air duct, taking $v^{2}=1071.8$, and $h_{\text {Local total }}$ can be calculated to be 738.3Pa.

(3) Other local resistance: As a general rule, when using air duct for ventilation, it can be considered to increase $h_{\text {other }}$ by $5 \%-10 \%$. If taking the maximum $10 \%$, the calculated $h_{\text {other }}$ is $73.8 \mathrm{~Pa}$.

(4) Air pressure at duct end:

$$
h_{\text {Dynamic }}=\frac{\gamma_{z} \times v^{2}}{2}
$$

Where, $\gamma_{z}$ is the specific gravity of air, $0.84 \mathrm{~kg} / \mathrm{m}^{3} ; \mathrm{v}$ is the average air velocity of the whole length of the air duct, taking $v^{2}=1071.8$, and $h_{\text {Dynamic }}$ can be calculated to be 336Pa. The final air supply volume of the fan and the total air pressure resistance of air supply are $2937 \mathrm{~m}^{3} / \mathrm{min}$ and $5619.1 \mathrm{~Pa}$, respectively.

\subsection{Ventilation equipment selection}

(1) Ventilation equipment selection

In order to ensure the ventilation rate, the fans selected according to the above calculation are as follows: adopt $1.5 \mathrm{~m}$ diameter air duct, and fan model of SDDY-1N013(A). The air volume range is from 1333 $\mathrm{m}^{3} / \mathrm{min}$ to $3000 \mathrm{~m}^{3} / \mathrm{min}$, and the air pressure range is from $1450 \mathrm{~Pa}$ to $6500 \mathrm{~Pa}$.

Adopt single-machine single-duct forced ventilation, install two axial fans (one for use and one for standby) 
$30 \mathrm{~m}$ outside the tunnel entrance, adopt $\varphi_{1.5 \mathrm{~m}}$ flexible ventilation duct, which will be extended with the advance of the tunnel face to the place about $5 \mathrm{~m}$ away from the tunnel face. The fresh air is forced into the working face through the flexible ventilation duct, and the pollution gases and dust in the tunnel are discharged out of the tunnel along the tunnel. When passing through gas enrichment sections, local fans are provided in the sections to make the air velocity in gas enrichment areas reach $1 \mathrm{~m} / \mathrm{s}$. See Table 3 for fans adopted.

Table 3. Table of Equipped Fans

\begin{tabular}{lllll}
\hline Fan model & $\begin{array}{l}\text { Air volume } \\
\left(\mathrm{m}^{3} / \mathrm{min}\right)\end{array}$ & $\begin{array}{l}\text { Air } \\
\text { pressure } \\
(\mathrm{Pa})\end{array}$ & $\begin{array}{l}\text { Power } \\
(\mathrm{kw})\end{array}$ & Quantity \\
\hline IN013(A) & 3000 & 6500 & 264 & 4 \\
IIN012.5 & 2580 & $/$ & 45 & 4 \\
\hline
\end{tabular}

Considering air leakage coefficient, high-altitude air correction coefficient and fan type selection, the maximum gas emission rate that can be diluted when the fan is equipped is calculated.

$$
Q_{\text {Actual }}=Q_{\text {Rated }} \times P \times K
$$

Where, $Q_{\text {Actual }}$ is the air volume actually required; $Q_{\text {Rated }}$ is the rated air volume of the fan, taking $3000 \mathrm{~m}^{3} / \mathrm{min}$; $\mathrm{P}$ is the air leakage coefficient, taking 1.14 ; $\mathrm{K}$ is the high-altitude air correction coefficient, taking 0.7. After calculation, it can be obtained that the air volume actually required is $1842 \mathrm{~m}^{3} / \mathrm{min}$.

$$
Q_{\text {gas }}=\frac{K \cdot A}{C_{1}-C_{0}}
$$

Where, $\mathrm{K}$ is the correlation coefficient, taking 2; $\mathrm{A}$ is the gas emission rate; $C_{0}$ is the gas concentration in the air supply, taking $0.00 \% ; C_{1}$ is the allowable gas concentration in the tunnel, taking $0.5 \%$; $Q_{\text {gas }}$ is the air volume required for diluting gas, taking $1842 \mathrm{~m}^{3} / \mathrm{min}$.

According to the actual situation, the gas emission rate is $4.61 \mathrm{~m}^{3} / \mathrm{min}$, and the maximum absolute gas emission rate that can be diluted by a single fan provided based on calculation is $6.61 \mathrm{~m}^{3} / \mathrm{min}$.

\section{(2) Power supply for ventilation}

Of the two power supplies of the main and standby fans, one is external power supply and the other is selfcontained power supply. When the external power supply fails, the self-contained power supply should be started and connected to the fan within $15 \mathrm{~min}$. When there is prior notice of power outage of the external power supply, it is necessary to make preparations for starting the self-contained power supply. Once the external power supply is stopped, the self-contained power supply is switched on in no time. Two generator sets (one is $456 \mathrm{KW}$ and the other is $500 \mathrm{KW}$ ) are provided on the left and right lines of Ningchan Tunnel respectively as standby power supplies for the fans of the two tunnels. The generators are run every ten days to check whether the circuits, oil and operating conditions are normal, so as to avoid damage caused by long-term unused standby power supply and ensure its good condition. Ensure that in case of power failure, the standby power supply can be started within $15 \mathrm{~min}$ to provide ventilation.

\section{Ventilation scheme}

\subsection{Ventilation equipment selection}

The two tunnels at the entrance of Ningchan Tunnel adopt blind heading, and trackless transportation is adopted for transportation inside the tunnel. The ventilation mode is forced ventilation, supplemented by explosion-proof jet fan ventilation. In order to ensure the ventilation effect and prevent gas from moving between tunnels, it is planned to excavate the transverse passage in the tunnel after the main tunnel is penetrated.

According to the requirements of relevant specifications of gas tunnel, in order to ensure the continuous ventilation of the tunnel, double fans and double air ducts are used for ventilation. The air ducts are antistatic and flame retardant, and the main air duct and the standby air duct are both extended to a position $5 \mathrm{~m}$ away from the tunnel face. The fans are powered by two power supplies (one generator with $456 \mathrm{KW}$ and one generator with $500 \mathrm{KW}$ are provided as standby power supplies for the two tunnels respectively), so as to ensure that when one power supply is stopped, the other power supply can be started within $15 \mathrm{~min}$ to ensure continuous ventilation. Each fan is equipped with an interlocked circuit breaker.

Local ventilation fans are set at places in the tunnel where gas accumulation easily occurs, such as lining section changes, transverse tunnel crossing, secondary lining jumbo, so as to increase the air velocity and prevent gas accumulation.

Establish ventilation management team to be responsible for daily maintenance of fans, power supplies and air ducts. Measure the air velocity on a regular basis to evaluate the ventilation effect, so as to achieve the best ventilation effect. Meanwhile, install an air velocity sensor at the return air flow $20 \mathrm{~m}$ away from the excavation face, so as to realize the combination of automatic and manual ventilation detection, and verify each other to ensure the accuracy of air measurement.

It is difficult to ventilate and exhaust smoke because of the downslope construction. Therefore, two $132 \mathrm{KW} \times 2$ axial-flow fans (one for use and one for standby) are set at the portal. Forced ventilation is adopted, and the diameter of air duct is $1.5 \mathrm{~m}$. The fans are installed outside the tunnel, more than $30 \mathrm{~m}$ away from the tunnel portal to avoid the circulation of dirty air. In addition, in order to speed up the ventilation circulation, gas sections are designed in the tunnel, and each widened section is provided with a $45 \mathrm{KW}$ explosion-proof jet fan to blow out the dirty air towards the tunnel portal, so as to speed up the discharge of the dirty air in the tunnel. The left and right lines are respectively provided with two sets, and the general layout of the tunnel fans is shown in Fig. 1. When the 
concentration of toxic and harmful gas in the tunnel is high, the standby fan is turned on at the same time to accelerate the gas discharge.

The fans in the gas work area should be provided with two power supplies, and equipped with interlocked circuit breakers. When one power supply stops supplying power, the other should be connected within $10 \mathrm{~min}$ to ensure the normal operation of the fans.

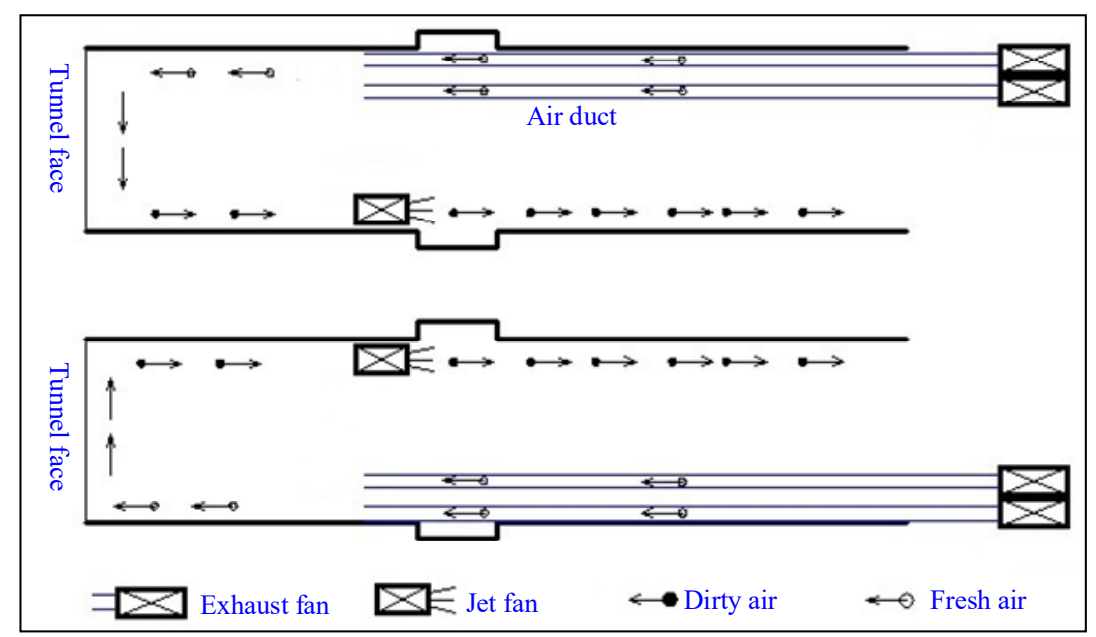

Fig. 1. Schematic Diagram of General Layout of Fans in Ningchan Tunnel

The gas tunnel should adopt antistatic and flameretardant air ducts. The distance from the air duct opening to the excavation working face should be no more than $5 \mathrm{~m}$, and the $100 \mathrm{~m}$ air leakage rate of air duct should not be more than $1 \%$. Construction ventilation should be uninterrupted, standby fans with the same performance should be provided.

\subsection{Treatment of local gas accumulation}

In the construction of gas tunnel, the following main measures can be taken to prevent gas accumulation:

(1) Improve the smooth blasting effect, make the tunnel wall as flat as possible, which can not only reduce the gas accumulation space, but also reduce the ventilation resistance, so as to make the ventilation flow smoothly;

(2) Spray concrete in time to seal the cracks and remaining blastholes in the rock wall to reduce the infiltration of gas into the tunnel;

(3) Increase air velocity to reduce the possibility of gas accumulation;

(4) Supply air to gas accumulation parts to disperse the gas.

In the process of construction, the following methods can be used to supply air to the gas accumulation parts to disperse the gas:

(1) Air duct branch discharge method

Add a "three-way" to the air duct near the place where gas is easy to accumulate (such as cave-in point) or install a small-diameter branch inner duct to supply air to the place where gas accumulates, as shown in Fig. 2 to exhaust accumulated gas.

(2) Forced-air exhausting method

Connect a branch on the high-pressure air duct, and set several nozzles on the branch pipe to exhaust the accumulated gas by using forced air. This method can also be used to prevent gas accumulation when cave-in occurs in the tunnel face or water gushing causes cave-in.

\subsection{Thermal insulation for tunnel in winter}

The maximum air supply by tunnel fans can reach $3000 \mathrm{~m}^{3} / \mathrm{min}$, and the local minimum temperature in winter can reach $-30^{\circ} \mathrm{C}$, but the temperature in the tunnel shall not be lower than $5^{\circ} \mathrm{C}$. According to the calculation, the required heat is:

$$
Q=c \times m \times\left(T_{1}-T_{2}\right) \times s=139513.5 \mathrm{~J} / \mathrm{min}
$$

KJZ-50 mine heating unit is used, which is mainly used for air heating. Finned tubes are used as heating elements, and the aluminum tape is tightly wound on the outer wall of the steel tube by using numerical-control wrapping equipment, so that the heat can be quickly and evenly transferred to the air by utilizing the highefficiency heat conduction performance of aluminum material. There are two control modes for constant temperature control: manual control and automatic control. The fans and steam control valves are adjusted cooperatively according to the inlet and outlet air temperature and the working environment temperature, so as to ensure the reliability and safety of the working environment.

\section{Engineering application effect}

After the occurrence of high gas in Ningchan Tunnel, the upgrading of the ventilation system was completed in June 2019, and the ventilation and gas concentration of the tunnel in July were monitored. See Table 4 and Fig. 2 for the monitoring results. By analyzing the monitoring results, it can be seen that the average gas emission from the left and right tunnel faces of Ningchan high gas tunnel from July 1, 2019 to July 31, 2019 is $0.18 \%$ (left) and $0.28 \%$ (right). When calculated with $2000 \mathrm{~m}^{3} / \mathrm{min}$ as 
the average air supply volume of the tunnel, the absolute gas emission rate from the left and right tunnels is about $3.6 \mathrm{~m}^{3} / \mathrm{min}$ (left) $5.6 \mathrm{~m}^{3} / \mathrm{min}$ (right). The ventilation scheme has good ventilation effect, which effectively reduces the concentration of tunnel gas and ensures the safety of tunnel construction.

Table 4. Air Measurement of Ningchan High Gas Tunnel

\begin{tabular}{|c|c|c|c|c|c|c|c|}
\hline \multirow{2}{*}{$\begin{array}{c}\text { Air measuring } \\
\text { location }\end{array}$} & \multirow{2}{*}{$\begin{array}{c}\text { Cross-sectional } \\
\text { area at air } \\
\text { measuring location } \\
\left(\mathrm{m}^{2}\right)\end{array}$} & \multicolumn{3}{|c|}{$\begin{array}{l}\text { Air meter readings at each measurement } \\
(\mathrm{m} / \mathrm{s})\end{array}$} & \multirow{2}{*}{$\begin{array}{l}\text { Average } \\
\text { air velocity } \\
(\mathrm{m} / \mathrm{s})\end{array}$} & \multirow{2}{*}{$\begin{array}{c}\text { Air } \\
\text { volume } \\
\left(\mathrm{m}^{3} / \mathrm{min}\right)\end{array}$} & \multirow{2}{*}{ Fan parameters } \\
\hline & & $\begin{array}{c}1 \mathrm{st} \\
\text { measurement }\end{array}$ & $\begin{array}{l}\text { 2nd } \\
\text { measurement me }\end{array}$ & $\begin{array}{c}\text { 3rd } \\
\text { asurement }\end{array}$ & & & \\
\hline $\begin{array}{l}\text { Inlet air of right } \\
\text { line tunnel face }\end{array}$ & 70 & 0.60 & 0.61 & 0.59 & 0.60 & 2520 & \multirow{2}{*}{$\begin{array}{c}\text { Fan power: } 132 \times 2 \mathrm{KW} \text {, } \\
50 \mathrm{~Hz} \text {; air duct } \\
\text { distance: } 980 \mathrm{~m} .\end{array}$} \\
\hline $\begin{array}{l}\text { Right line return } \\
\text { air }\end{array}$ & 84 & 0.51 & 0.53 & 0.54 & 0.527 & 2656 & \\
\hline $\begin{array}{l}\text { Inlet air of left line } \\
\text { tunnel face }\end{array}$ & 70 & 0.57 & 0.55 & 0.58 & 0.557 & 2338 & \multirow{2}{*}{$\begin{array}{c}\text { Fan power: } 132 \times 2 \mathrm{KW} \text {, } \\
50 \mathrm{~Hz} \text {; air duct } \\
\text { distance: } 1020 \mathrm{~m} .\end{array}$} \\
\hline Left line return air & 84 & 0.49 & 0.52 & 0.51 & 0.507 & 2553 & \\
\hline
\end{tabular}

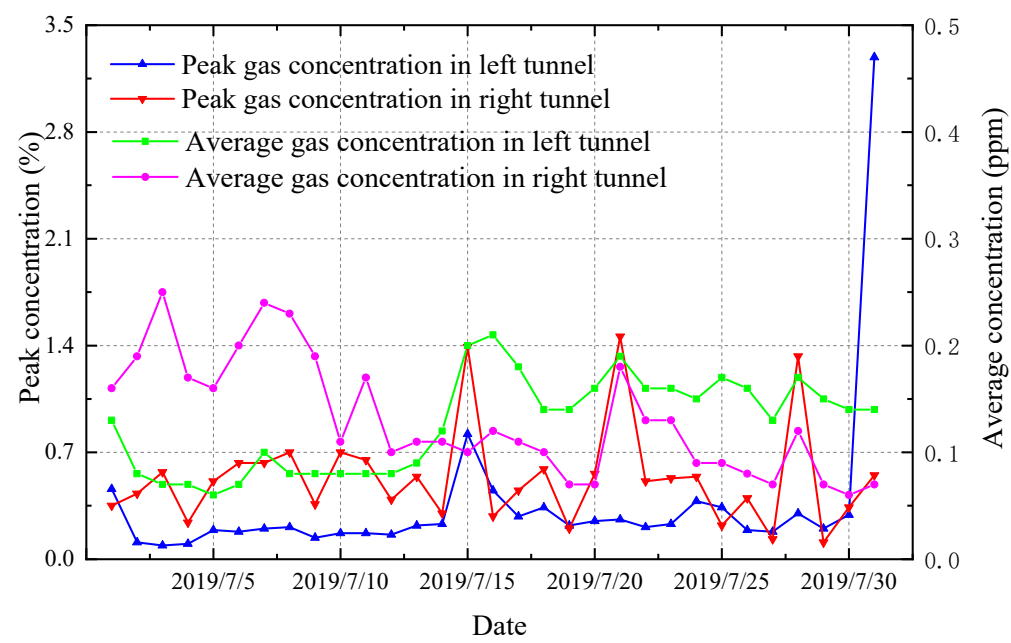

(a) Real-time Monitoring Curve of Gas Concentration in Ningchan Tunnel

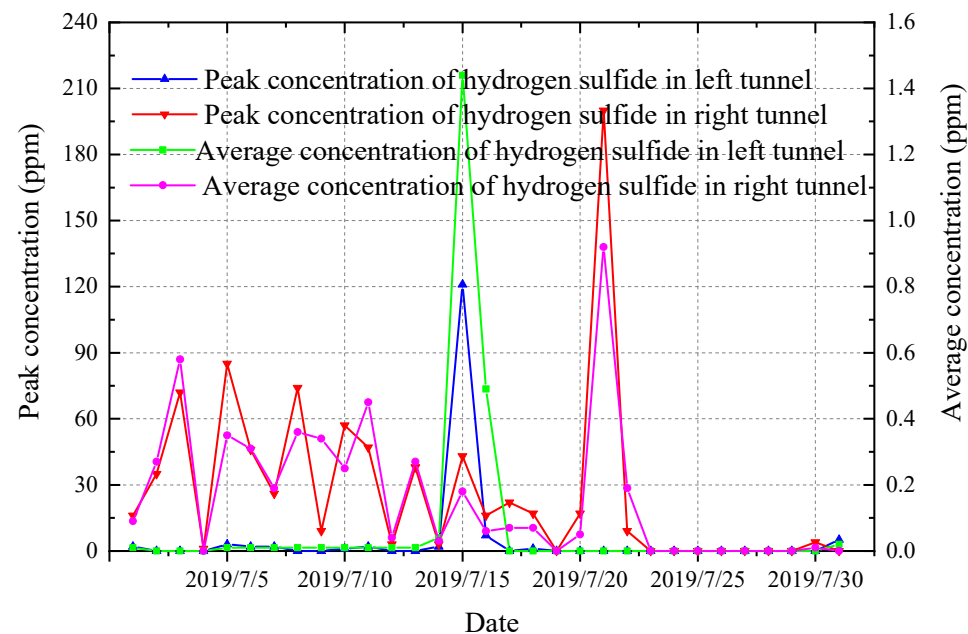

(b) Real-time Monitoring Curve of Hydrogen Sulfide Concentration in Ningchan Tunnel

Fig. 2. Real-time Monitoring Results of Toxic and Harmful Gases in Ningchan Tunnel

\section{Conclusions}

According to the characteristics of Ningchan high gas tunnel, such as cold, high altitude and long tunnel body, construction ventilation is not only the key to of tunnel construction safety but also a challenge. Through the research on ventilation scheme of high gas tunnel construction in cold and high altitude areas, the rational allocation of high power fans and the adoption of double-air-duct ventilation mode not only meet the air volume requirements of high gas tunnel, but also avoid the influence of high altitude on ventilation effect. In winter construction, the mine heating unit is equipped, which can not only meet the ventilation requirements of 
high gas tunnel construction, but also ensure the temperature in the tunnel to meet the construction requirements.

The engineering application results show that the ventilation scheme of Ningchan high-altitude gas tunnel construction is reasonable and feasible. After the modification according to the ventilation scheme, the average values of gas emission from the left and right tunnel faces are $0.18 \%$ (left) and $0.28 \%$ (right), respectively, and the ventilation effect is good, which effectively reduces the concentration of tunnel gas and ensures the safety of tunnel construction.

\section{Acknowledgments}

This work is jointly supported by the Science and Technology Project of Transportation Department of Qinghai Province (No. 2020-01).

\section{References}

1. Li Yongsheng. Development of Ventilation Methods for Mountain-crossing Tunnels during Construction[J]. Tunnel Construction, 2010, 30(5): 569-572.

2. WangYuntao, Yang Min, Lu Hao, Jiang Si ang. Application of Gas Drainage in Construction of Huayingshan Tunnel of $\mathrm{Yu}$-Guang Expressway[J]. Technology of Highway and Transport, 2017, 33(02): 89-92+96.

3. Wang Xiaomin, Fang Yong. Construction Ventilation Scheme for the Huayingshan ExtraLong Tunnel on the Nanchong-Dazhu-Liangping Expressway[J]. Modern Tunnel Ling Technology, 2013(4): 188-196.

4. Wu Xuedu. Ventilation technology for construction of Zhegushan plateau tunnel[J]. West-China Exploration Enginering, 2004(5): 105-107.

5. Ding Hao, Sun Lidong, Li Yong, Xiao Bo. Design and Construction of Tunnel Running Across Sections with Toxic Gases[J]. Technology of Highway and Transport, 2010(06): 111-114+125.

6. Wei Qun. Discussion on some problems of ventilation in construction of long hard rock highway tunnel[J]. Sichuan Architecture, 2017(4): 101-102.

7. Han Zhi. Idea and method of ventilation design for highway tunnel[J]. Chinese Journal of Underground Space and Engineering, 2005, 25(3): 464-466.

8. Shen Hao-kun. Application analysis of ventilation technology in highway tunnel[J]. Technology and Market, 2016, 23(12): 123-123.

9. Wu Zhi-hua, Lin Guo-hui, Chen Yan-qiong. The Design of Construction Ventilation Technique Project for Super-long Highway Tunnel[J]. Journal of Hunan Institute of Engineering: Natural Science Edition, 2016, 26(1): 81-85.
10. Guo Hongyan. Analysis of Influences of Section Size on Stability of High -gas Tunnel Wall Rocks[J]. Technology of Highway and Transport, 2015(04): 127-131.

11. Huang Gen-qi. Ventilation technology of long tunnel in alpine region of Qinghai Tibet Plateau[J]. Railway Standard Design, 2007(1): 74-76.

12. Sichuan Highway Planning, Survey, Design and Research Institute Ltd. Specifications for Design and Construction of Highway Tunnels with Gas JTGT 3374-2020[S].Bei Jing: 2020.

13. Sun Ying, Liu Xiao-xia. Design updating of ventilation system of highway tunnel under construction under new code[J]. Highway Tunnel, 2015(004): 37-42. 